\title{
MODOS DE SUBJETIVAÇÃO DO TIPO SUJEITO E DO TIPO INTENSIDADE: MOVIMENTOS COTIDIANOS EM INSTITUIÇÕES DE EDUCAÇÃO INFANTIL
}

\author{
Maritza Maciel Castrillon Maldonado ${ }^{\mathrm{i}}$
}

\begin{abstract}
Resumo: Professoras. Estagiárias. Crianças. Como nos tornamos o que somos? Ou, o que estamos fazendo de nós mesmos e dos outros que estão aos nossos cuidados? Analisar essas questões é o que nos movimenta neste texto. Analisá-las não apenas no sentido de problematizar "o" sujeito professora, ou "o" sujeito estagiária, ou "o" sujeito criança, em suas identidades ou identificações, criando-lhes uma pretensa verdade. Analisar essas questões no sentido de interpelar alguns processos de subjetivação que constituem os sujeitos ou seus modos de existência e pensar uma nova forma de subjetividade, que recuse a individualidade, que seja singular, que potencialize a vida. Esse é nosso propósito neste texto. Como faremos isso? Narrando acontecimentos cotidianos que movimentam espaçostempos de instituições de Educação Infantil e constituem, ora sujeitos, ora intensidades. Esses acontecimentos foram percebidos a partir de práticas da disciplina Estágio Supervisionado I do curso de Pedagogia da Universidade do Estado de Mato Grosso (UNEMAT), campus Universitário de Cáceres.
\end{abstract}

Palavras-chave: Estágio; Educação Infantil; Subjetivação.

\section{MODES OF SUBJECTIVATION OF THE SUBJECT-TYPE AND THE INTENSITY- TYPE: DAILY MOVEMENTS IN CHILD EDUCATION INSTITUTIONS}

\begin{abstract}
Teachers. Trainees. How have we become who we are? Or, what have we been doing of ourselves and the others we look after? This paper analyzes these issues but not as an attempt to problematize either "the" teacher-subject or "the" trainee-subject or "the" child-subject, and either their identities or their identifications, by providing them with a supposed truth. It is an analysis aimed at approaching some of the processes of subjectivation that have constituted subjects or their modes of existence, and thinking of a new form of subjectivity that denies individuality, is singular, and potentializes life. This is the purpose of this paper. How can we do that? By narrating daily events that have both driven the time-spaces of Child Education institutions and constituted either subjects or intensities. These events have been perceived in the practices of the discipline of Supervised Training I of the Pedagogy course on the Caceres campus of the State University of Mato Grosso (UNEMAT).
\end{abstract}

Keywords: Training; Child Education; Subjectivation.

Discutir acontecimentos cotidianos que movimentam espaçostempos na Educação Infantil e que constituem sujeitos no período em que o estágio supervisionado acontece é um desafio, considerando os muitos aspectos e dimensões que circundam o tema. Necessário se 
faz, assim, logo de início, dizer como tratamos a questão. Para isso, reportamo-nos ao alerta trazido por Foucault: precisamos pensar uma subjetividade que resista à individualidade:

Gostaria de dizer que o problema político, ético, social e filosófico de nossos dias não consiste em tentar liberar o indivíduo do Estado e do tipo de individualização a ele vinculado. Temos que promover novas formas de subjetividade, recusando o tipo de individualidade que nos foi imposto durante séculos (FOUCAULT, 1989, p. 10).

A questão política para Foucault consiste em promover novas formas de subjetividade que recusem a individualidade. Aliados ao seu pensamento, outros autores também pensam na possibilidade de outras formas de constituição dos sujeitos. Para Benjamin (1993), necessitamos de "ar fresco". Precisamos sair da "caixa de veludo", despejarmo-nos no mundo e criar novos espaços, mudar o ponto de observação. Calvino (1990, p.19), reportando-se a Perseu, diz que devemos voar para outro espaço:

Não se trata absolutamente de fuga para o sonho ou o irracional. Quero dizer que preciso mudar de ponto de observação, que preciso considerar o mundo sob uma outra ótica, outra lógica, outros meios de conhecimento e controle. As imagens de leveza que busco não devem, em contato com a realidade presente e futura, dissolver-se como nos sonhos (...).

Com esse mesmo clima de crença no mundo, citamos também Gilles Deleuze e Félix Guattari. Eles dizem que, para os enunciados, como para os desejos, a questão é nunca reduzir o inconsciente, interpretá-lo ou fazê-lo significar segundo uma árvore. Para eles, a questão é produzir inconsciente e, com ele, novos enunciados, outros desejos (1995, p. 28).

O desafio desses autores impulsiona-nos a olhar o cotidiano de instituições de Educação Infantil e perceber como as subjetividades estão sendo constituídas naquele espaçotempo. É a isso que nos propomos a fazer neste texto. Olhar o cotidiano a partir dos múltiplos olhares das acadêmicas do curso de Pedagogia que cursaram a disciplina Estágio Supervisionado I Educação Infantil - e perceber como as professoras de instituições de Educação Infantil, as estagiárias da UNEMAT e as crianças se relacionam e se constituem.

\section{Modos de subjetivação do tipo sujeito e do tipo intensidade: narrativas que constituem}


Neste texto, deixamos de lado o conceito moderno de sujeito, compreendido como categoria fundante, com identidade fixa e uma substância interior. Concebemos o sujeito como aquele que é constituído nos agenciamentos históricos, com identidades múltiplas, flexíveis, cambiantes, flutuantes, mutantes e produzidas a cada novo encontro ${ }^{\mathrm{ii}}$, na diferença.

Assim, falamos da constituição de sujeitos como processos de subjetivação, os quais se concretizam na produção de modos de existência, na medida em que as linhas do fora apresentam incontáveis ramificações e que estas afetam os seres de modo distinto. A subjetividade, seguindo esse pensamento, é produzida no meio, é um modo de existir. "A subjetivação, como processo, é uma individuação, pessoal ou coletiva, de um ou de vários" (DELEUZE, 1992, p. 143). No entanto, existem muitos tipos de individuação. Há individuações do tipo "sujeito", aquele que acumula rastros no decorrer de sua vida para constituir um "Eu" soberano, mas há individuações do tipo acontecimento, sem sujeito: “um vento, uma atmosfera, uma hora do dia, uma batalha..." (id). Nesta última concepção, são os conjuntos de intensidades que afetam os seres. Essas intensidades reluzem, cintilam por onde passam. Narraremos, a seguir, alguns agenciamentos vivenciados nos espaçostempos cotidianos das instituições de Educação Infantil onde o estágio se desenvolveu. Agenciamentos do tipo sujeito e agenciamentos do tipo acontecimento, intensidade.

Iniciamos nossa conversa problematizando: como crianças de zero a cinco anos iniciam os agenciamentos com o mundo nos espaçostempos de instituições de Educação Infantil? Para compreender esse processo de constituição da subjetividade da criança, reportamo-nos a Guattari, que, em conversa com Rolnik, diz:

Uma criança, por menor que seja, vive sua relação com o mundo e sua relação com os outros de um modo extremamente produtor e criativo. É a modelização de suas semióticas através da escola que a conduz a uma espécie de processo de indiferenciação (GUATTARI; ROLNIK, 2005, p. 162).

Por meio da escola, segundo o autor, a criança é inserida em um mecanismo de economia desejante; a criança é inserida na máquina de produção da individualidade, da identidade. A identidade "é aquilo que faz passar a singularidade de diferentes maneiras de existir por um só e mesmo quadro de referência identificável” (id, p. 80); a individualidade é o efeito da alienação dos processos de singularização (id, p. 165). A escola é entendida por Guattari como um equipamento coletivo que exerce a função de operário na máquina de 
formação da subjetividade capitalística. Essa subjetividade capitalística produz uma nova conduta, um novo modo para as relações humanas. Dita as normas de como trabalhar, como ser ensinado, como amar, como brincar, como se mover, como falar...

Ela fabrica a relação com a produção, com a natureza, com os fatos, com o movimento, com o corpo, com a alimentação, com o presente, com o passado e com o futuro - em suma, ela fabrica a relação do homem com o mundo e consigo mesmo. Aceitamos tudo isso porque partimos do pressuposto de que esta é "a" ordem do mundo, ordem que não pode ser trocada sem que se comprometa a própria ideia de vida social organizada (Guattari e Rolnik, 2005, p. 51).

O conhecimento, nesse contexto, é esvaziado de singularidade. A produção de subjetividade capitalística tem como propósito eliminar os processos de singularização. "Tudo o que surpreende, ainda que levemente, deve ser classificável em alguma zona de enquadramento, de referenciação" (id. p. 52). Guattari prossegue, dizendo que os professores (não somente eles, mas também os meios de comunicação de massa) são muito dotados para esse tipo de prática. A escola trabalha incansavelmente para assegurar esse processo de subjetivação capitalístico.

Escola exercendo a função de operário na máquina de formação da subjetividade capitalística? O espaçotempo da educação infantil, instituição que recebe crianças tão pequenas, de zero a cinco anos, tem também a função de ditar normas de como ser e estar no mundo?

\section{Economia desejante: um currículo marcado pelo esvaziamento da singularidade}

Iniciamos as aulas de Estágio Supervisionado 1 - Educação Infantil, enfatizando a necessidade de ter como eixo da regência nas turmas de quatro e cinco anos a Literatura Infantil, focando os gêneros histórias infantis, poesias e músicas. Estruturamos os seis grupos, que realizaram essa etapa de sua formação em Instituições de Educação Infantil da rede municipal de ensino da cidade de Cáceres (MT).

Antes de as acadêmicas irem a campo, orientamos os seis grupos para que realizassem uma sondagem no sentido de identificar quais histórias, músicas e poemas as crianças já sabiam. O objetivo dessa sondagem foi diagnosticar os títulos dos gêneros literários que já haviam sido trabalhados com as crianças para que o planejamento das estagiárias trouxesse algo de novo. 
Em relação às músicas cantadas, a observação direta nas salas e as anotações foram suficientes para alcançarmos nosso objetivo. Quanto às histórias e poemas, as estagiárias perguntaram para as próprias crianças, individualmente e longe das demais, de quais histórias e poemas mais gostavam. As perguntas que fizeram para as crianças foram: você gosta de ouvir histórias? De qual história que você ouviu você mais gosta? E algum poema, você conhece algum?

Ao final do período de observação/monitoria, os grupos levaram para a sala o resultado da sondagem. Elaboramos um gráfico para cada escola e reunimos os dados para apresentar neste texto. O resultado nos surpreendeu. Foram entrevistadas, em média, 20 crianças por escola, totalizando, 120 crianças de quatro e cinco anos respondendo as questões. As histórias que apareceram com maior incidência nas seis escolas foram Chapeuzinho Vermelho (58\%), Os três porquinhos (32\%); as fábulas A formiga e a cigarra, A raposa e a lebre e A raposa e as uvas (8\%), dentre outras; e algumas de cunho religioso, que não passaram de $2 \%$. Nota-se que a preferência por Chapeuzinho Vermelho superou, de longe, as outras histórias.

Em relação aos poemas, as crianças de quatro escolas disseram não conhecer nenhum; em duas escolas, poucas crianças lembraram-se, sem saber os nomes: Borboletas (de Vinicius de Moraes), Leilão de jardim (de Cecília Meireles), Batatinha quando nasce e um dedicado às mães, que as estagiárias não conseguiram identificar.

No período de observação/monitoria em que as estagiárias do curso de Pedagogia passaram 48 horas nas instituições de Educação Infantil, diagnosticaram as músicas que embalam aqueles cotidianos. As músicas cantadas com maior incidência, praticamente todos os dias e em todas as escolas, foram: Borboletinha; Bom dia coleguinha, como vai; Meu lanchinho; Piui-chá-chá-chá. Músicas também cantadas: Um, dois, três indiozinhos e Abecedário da Xuxa.

Selecionar histórias infantis que trazem uma moral dogmática, poemas de ensino (cores, números, letras) e músicas disciplinadoras de corpos e mentes para compor o currículo da Educação Infantil traz, a nosso ver, uma concepção clara do sujeito criança que está se constituindo. Em Chapeuzinho Vermelho, a criança que desvia do caminho do bem, desobedecendo à mãe, é engolida pelo lobo mau; em Os três porquinhos, sair do mundo dos prazeres (música) para inserir-se no mundo do trabalho é condição que possibilita que o lobo não destrua a casa; nas fábulas de La Fontaine, a moral é antecipada; a música Os indiozinhos serve para aprenderem os numerais e sua ordem; a Xuxa, para aprenderem $O$ abecedário; o trenzinho do piuí-chá-chá-chá para ficarem em fila de modo a cumprir com rotina da escola 
(para o lanche, para o parque, para o almoço, para o jantar, para o sono); O lanchinho para ficar fortinho; e A borboletinha, a campeã entre as preferências das crianças, para divertir.

Consideramos esses, alguns exemplos das escolhas feitas pelos discursos das escolas em questão, que contribuem para que aconteça o esvaziamento da singularidade. São alguns exemplos de que o modelo ideal de escola preconizado na modernidade, tal qual Guattari nos apresenta, está também no cotidiano do espaçotempo da Educação Infantil como um equipamento coletivo que exerce a função de operário na máquina de formação da subjetividade capitalística. Essa subjetividade capitalística produz uma nova conduta, de economia de desejos. Economia de desejos? Essa questão forçou o pensamento das estagiárias a pensar seus planejamentos, suas práticas, seu processo de constituição como professoras da Educação Infantil.

\section{Singularização: potência de vida no cotidiano da Educação Infantil}

Os questionamentos trazidos pelas estagiárias em sala de aula permearam a seguinte questão: não temos, então, como viver fora dessas amarras da relação saber/poder, das amarras da disciplinaridade, das amarras do processo de subjetivação capitalístico? Essa dúvida levouas a pensar. Com essa dúvida, foram para a escola e continuaram o estágio, agora selecionando outras histórias, músicas, poemas, temas e encantos para se relacionarem com as crianças na fase de Regência. Elaboraram planejamentos, projetos, enredos, com dedicação e compromisso tanto com as crianças quanto com sua formação. Foi no desenvolvimento dessas ações que perceberam que, embora a escola exerça a função de operário na máquina de formação da subjetividade capitalística, ela não consegue funcionar tão eficientemente a ponto de interromper, ou encolher completamente o desejo da criança.

As crianças que movimentaram o cotidiano dos espaçostempos das instituições de Educação Infantil naquele período de estágio nos deram provas de que não estamos mergulhados em uma espécie de fatalidade.

Uma acadêmica, desenvolvendo o Projeto Meu nome, minha vida com crianças de quatro anos, conciliou o tema com a data comemorativa Dia das Mães. Solicitou às crianças que indagassem os pais ou responsáveis sobre a escolha de seus nomes; filmou as crianças falando aquilo que lhes disseram; na hora do vídeo, apresentou o filme produzido, tendo as 
crianças como protagonistas; fizeram carteiras de identidade com fotos impressas em preto e branco, coloridas pelas crianças...Tudo permeado por muitas músicas, brincadeiras e poemas. Não, não é o que ela fez com o tema que nos importa relatar aqui. O que nos interessa foi seu primeiro contato com as crianças, momento acompanhado por mim, professora orientadora do Estágio. Nesse primeiro encontro, empolgada, falou que passaria seis dias com aquela sala e que, no domingo seguinte (contou os dias da semana juntamente com as crianças até chegar domingo), seria o Dia das mães, por isso, durante a semana, fariam um trabalho dedicado a ela. Repetiu a contagem dos dias que faltavam para chegar o domingo, dia das mães. Ela disse: “Então, só faltam seis dias para domingo. Só faltam seis dias para o dia das mães". Julia, uma das crianças da sala, falou para a estagiária: "Não, professora, domingo é o dia em que eu vou visitar o meu pai na cadeia”.

Indo além do "sonho feliz de cidade" ou do "final feliz" dos contos de fada, a vida continua a pulsar no cotidiano de instituições de Educação Infantil. Sua relação com o mundo entra na sala de aula com todos os desejos de que o domingo chegue logo para que o encontro esperado aconteça. E o Dia das Mães? Ah! A mãe, Júlia tem todos os dias em sua casa.

Outro caso, em outra escola, com outras crianças e o mesmo tema: Dia das Mães. A professora da sala pediu que a estagiária ensaiasse o seguinte poema com as crianças:
Mamãe me plantou
Mamãe me regou
Me fez crescer
Mamãe é uma flor
Mamãe é o amor
É o meu viver

João Pedro, de três anos, recusou-se veementemente a declamar o poema com os colegas, argumentando: "Minha mãe não é uma flor. Minha mãe é a Alessandra”. A estagiária fez novas investidas, mas João continuou emburrado no seu canto, recusando-se a ensaiar. A professora da sala foi chamada para conversar com João e convenceu-o, argumentando que a mamãe iria ficar triste se ele não apresentasse; porém, via-se na fisionomia do menino que ele não estava contente com aquela mãe-flor.

Outra estagiária, em outro espaçotempo, desenvolvia o tema "frutas" com as crianças de três anos. Levou mudas das plantas que seriam assuntos abordados naquele dia. Levou as próprias frutas, contando histórias. Comeram frutas todos os dias. Fez o teatro inventado 
"saladinha de frutas", com as crianças como personagens, com falas e fantasias. Fez a salada de frutas ao final. Experimentaram gostos, cores e texturas... Fizeram e aconteceram naquela semana! Mas o que paralisou a história? A estagiária perguntou: "Para a bananeira produzir bananas, o que temos que fazer com os pezinhos?", esperando que as crianças respondessem regar. No entanto elas, que prestavam atenção na sua curiosa apresentação com fantoche, bateram os pezinhos no chão. Primeiro uma, duas ou três... depois, todas.

Nesse sentido, nós, educadoras e educadores, precisamos nos dar conta de que estamos trabalhando nessa maquinaria que tem por intenção produzir a subjetividade capitalística - ou o modo de subjetivação do tipo sujeito -, mas que também pode produzir algo novo, que quebre, que rompa com o decalque que nos constitui. Podemos deixar a máscara cair, desviar, arriscar, tentar, "criar condições para a produção de um novo tipo de subjetividade, que se singulariza e que encontra as vias de sua especificação" (GUATTARI; ROLNIK, 2005, p. 58). Nós, educadoras e educadores, trabalhamos para o bom funcionamento dessa maquinaria que aniquila com a singularização. Que continuemos trabalhando nela, sabendo que somos produtores de subjetividades. Que produzamos intensidades no processo educacional, capazes de preservar "toda a riqueza de sensibilidade e de expressão própria da criança" (id. p. 64).

Propomos, então, que tentemos um processo de singularização no contexto educacional. Pensamos que um grande exemplo desse processo de singularização seja expresso nos poemas de Manoel de Barros. Animando as pedras do seu quintal, o poeta desencadeia uma nova e dinâmica maneira de ouvir. Segundo Guattari,

um processo de singularização da subjetividade pode ganhar imensa importância, exatamente como um grande poeta, um grande músico, um grande pintor, que, com suas visões singulares da escrita, da música ou da pintura, podem desencadear uma mutação nos sistemas coletivos de escuta $\mathrm{e}$ de visão (id. p. 65).

O poeta desencadeia aquilo que requer Guattari: uma nova cartografia do desejo. Manoel de Barros, com seus poemas, apresenta o seu devir-criança, os seus atravessamentos. E mais: apresenta seu devir-impessoal, seu acontecimento, seu agenciamento, sua relação de imanência com a vida, mesmo depois de passar pelo processo de subjetivação capitalístico. Apresenta a intensidade de sua vida. Vale citar o próprio Manoel de Barros (2003, s/p.) para pensar como é possível compor uma cartografia do desejo. 
(...) Quando eu era criança eu deveria pular muro do vizinho para catar goiaba. Mas não havia vizinho. Em vez de peraltagem eu fazia solidão. Brincava de fingir que pedra era lagarto. Que lata era navio. Que sabugo era um serzinho mal resolvido igual a um filhote de gafanhoto. Cresci brincando no chão, entre formigas. De uma infância livre e sem comparamentos. Eu tinha mais comunhão com as coisas do que comparação. Porque se a gente fala a partir de ser criança, a gente faz comunhão: de um orvalho e sua aranha, de uma tarde e suas garças, de um pássaro e sua árvore. Então eu trago das minhas raízes crianceiras a visão comungante e oblíqua das coisas. Eu sei dizer sem pudor que o escuro me ilumina. É um paradoxo que ajuda a poesia e que eu falo sem pudor. Eu tenho que essa visão oblíqua vem de eu ter sido criança em algum lugar perdido onde havia transfusão da natureza e comunhão com ela. Era o menino e os bichinhos. Era o menino e o sol. O menino e o rio. Era o menino e as árvores.

Nós, educadoras e educadores, podemos iniciar um processo de desencadeamento dessa cartografia, desse mundo de comunhão, "sem comparamentos", ou contentar-nos em podar os desejos, reproduzir decalques, atribuir identidades. Nossa função, como produtores de cartografias, deve permitir "captar todos os impulsos de desejo, todas as inteligências, não para fazê-las convergir num mesmo ponto central arborescente, mas para dispô-las num imenso rizoma, que atravessará todas as problemáticas sociais, tanto em nível local, regional, quanto em nível nacional e internacional” (GUATTARI; ROLNIK, 2005, p. 203).

Captar os impulsos, ter sensibilidade para ver, ouvir e sentir aquilo que está à nossa frente. Ver, ouvir e sentir a menina que quer visitar o pai na cadeia no dia das mães; ver, ouvir e sentir o menino que não quer que a mãe seja uma flor; ver, sentir e ouvir os pés que não produzem bananas, mas que batem no chão. Que novas subjetividades sairiam do desenvolvimento desses paradoxos do sentidos na Educação Infantil? A subjetividade singular da criança que movimenta o cotidiano do espaçotempo da Educação Infantil poderia ir além do processo de subjetivação capitalístico? Questões como essas permearam, inquietaram, colocaram a pensar as estagiárias que movimentaram o espaçotempo de instituições de Educação Infantil nesse período de sua formação.

\section{Referências}

BARROS, Manoel. Memórias Inventadas: a Infância. São Paulo: Planeta, 2003.

BENJAMIN, Walter. Obras escolhidas: Magia e Técnica, Arte e Política. 6 ed. São Paulo: Brasiliense, 1993. 
CALVINO, Ítalo. Seis propostas para o próximo Milênio: lições americanas. Tradução Ivo Barroso. São Paulo: Companhia das Letras, 1990.

DELEUZE, Gilles. Diferença e Repetição. Rio de janeiro, Graal: 1988.

DELEUZE, Gilles. Conversações. Tradução Peter Pál Pelbart. Rio de Janeiro, Ed. 34: 1992.

DELEUZE, Gilles \& GUATTARI, Félix. Mil Platôs. Capitalismo e esquizofrenia. Vol. 1. Tradução de Aurélio Guerra Neto e Célia Pinto Costa. - Rio de Janeiro: Ed. 34, 1995.

GUATTARI, Félix \& ROLNIK, Suely. Micropolítica: Cartografias do desejo. 7 ed. Petrópolis: Vozes, 2005.

FOUCAULT, Michel. Dois ensaios sobre o poder. In: Michel Foucault: Un Parcours Philosophique (Dreyfus, Hubert e Rabinow Paul), Paris. Ed Gallimard (tradução Lília Vale e Sílvia Aguiar, UFF, 1989, mimeo).

\footnotetext{
${ }^{\text {i }}$ Professora do PPGEdu e coordenadora do Ateliê de Imagem e Educação - AIE - da Universidade do Estado de Mato Grosso - UNEMAT.

ii Para Deleuze, é na intensidade da diferença que se produz o encontro mas, "não são os deuses que são encontrados; mesmo ocultos, os deuses não passam de formas para a recognição. O que é encontrado são os demônios, potências do salto, do intervalo, do intensivo ou do instante, que só preenchem a diferença com o diferente; eles são os porta-signos. E é o mais importante: da sensibilidade à imaginação, da imaginação à memória, da memória ao pensamento - quando cada faculdade disjunta comunica à outra a violência que a leva a seu limite próprio - é a cada vez uma livre figura da diferença e que desperta a faculdade, e a desperta como o diferente desta diferença”. (DELEUZE, 1988, p. 238)
} 